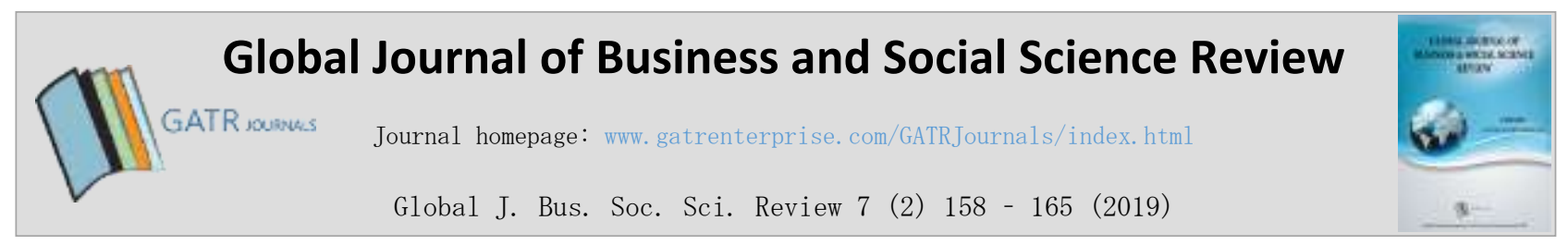

\title{
Access to Information of Disabled People on the Web: A Dispute between Accessibility and Digital Rights Management
}

\author{
Wariya Lamlert ${ }^{1}$, Oranuch Sawetrattanasatian ${ }^{2} *$ \\ ${ }^{1}$ Graduate School of Law, National Institute of Development Administration, \\ Serithai Rd. Bangkapi, 10240, Bangkok, Thailand \\ ${ }^{2}$ Department of Library Science, Faculty of Arts, Chulalongkorn University, \\ Phyathai Rd. Patumwan, 10330, Bangkok, Thailand
}

\begin{abstract}
Objective - The study aims to explore the dispute between accessibility and Digital Rights Management (DRM) for disabled people in accessing information on the Web. More specifically, this paper explores the challenges DRM has placed on them.

Methodology/Technique -This study inspects the controversial interaction between accessibility and DRM in relation to disabled people's access to information on the Web using document analysis from a socio-legal perspective. Further, the black-letter law of some widely known and internationally cited regulations are used in the investigation and discussion.

Findings \& Novelty- It is argued that the regulations which are beneficial to the accessibility of disabled people are overruled by DRM. More specifically, the challenges posed by DRM include: (1) Negligence of disabled people's rights, (2) Conflict of accessibility, and (3) Ignorance of copyright-related exceptions. This study is a cross disciplinary study probing the issue of disabled people in both legal studies, through relevant legislation, and information studies, through the topic of information access on the Web. It examines and analyses major regulations issued by leading organizations across the two disciplines. The findings of this study may be beneficial to knowledge and practice to bridge the gap of human rights for information access, particularly for disabled people, and argues that both information and legal professionals should be responsible for this.
\end{abstract}

Type of Paper: Review

Keywords: Accessibility; Digital Rights Management; Disabled People; Information Access, Web.

Reference to this paper should be made as follows: Lamlert, W.; Sawetrattanasatian, O. (2019). Access to Information of Disabled People on the Web: A Dispute between Accessibility and Digital Rights Management, Global J. Bus. Soc. Sci. Review, 7 (2): 158 - 165. https://doi.org/10.35609/gjbssr.2019.7.2(7)

JEL Classification: D83, K38, L86, O34

\section{Introduction}

Access to information is important to everyone, including disabled people. This is because information can assist in achieving goals in things such as education, careers, or personal well-being.

\footnotetext{
* Paper Info: Revised: March 14, 2019

Accepted: June 22, 2019

* Corresponding author: Oranuch Sawetrattanasatian

E-mail: oranuch.s@chula.ac.th

Affiliation: Faculty of Arts, Chulalongkorn University, Thailand
} 
The Internet, particularly the World Wide Web (WWW) or, the Web, is a popular source of information due to its ubiquity, compatibility, and abundance of information in different content and formats. With respect to disabled people, digital publishing not only provides them with more opportunities to access information, it may be their only means of access (Brewer \& Sajka, 2013). Therefore, it is necessary that the Web is accessible to everyone.

The Web is easy to modify and this has provoked copyright holders' attention which has resulted in Digital Rights Management (DRM) measures being put in place to prevent unauthorized access and use of information (Tran, 2016). From the introduction of DRM, access to and use of copyrighted works on the Web has become obstructed. This issue is made worse upon the official adoption of DRM as a Web standard (Kastrenakes, 2017). The application of DRM disturbs the accessibility of disabled people to the Web which is inconsistent with the overall purpose of many regulations - standards, laws, conventions, and treaties. This study therefore aims to examine the relationship between accessibility and DRM and the impact this has on the access of disabled people to the Web. More specifically, the study aims to identify the challenges DRM poses for access. This paper not only contributes to an understanding of their obstacles that DRM causes, it also proposes solutions to overcome these hindrances for the equalization of disabled people's opportunities to access information on the Web.

The literature review is presented in the next section to provide a background concerning DRM and the regulations used in the study. Following this, the paper describes how the research was conducted and provides a discussion of the findings. The paper concludes with some proposed recommendations and suggestions for further research.

\section{Literature Review}

DRM is a mechanism used for any digital content (e.g. e-books, movies, databases, websites, or some other sources of information) to protect, primarily, copyright as well as moral rights (Dingledy \& Matamoros, 2016). It consists of Technological Protection Measures (TPMs) and Rights Management Information (RMI), and when potential obstacles to access are considered, the former is mainly implied (Ficsor, 2010). Despite its acclaimed benefits for the protection of copyrighted work, many opponents to DRM are concerned that DRM may impose hurdles to information access, particularly among those with disabilities (Giannoumi, Land, Beyene, \& Blanck, 2017), through its functions of prevention, restriction, deterrence, and detection (Tran, 2016). Recently, Encrypted Media Extensions (EME), a form of DRM focusing on audio and video information, has been officially adopted in HTML5, the mark-up language used for web pages. This has increased tension surrounding the use of DRM and marks an increasing use of DRM on the Web (Halpin, 2017). DRM has changed the way the Web was once experienced and has made it more restricted preventing certain use of content or technologies (Daubs, 2017).

Having regard to the theories of equity and non-discrimination, disabled people should be guaranteed access to information since information is advantageous to their lives. However, the introduction and application of DRM seemingly opposes the purposeful intention of some internationally recognized regulations. These regulations include the Convention on the Rights of Persons with Disabilities (CRPD), Web Content Accessibility Guidelines 2.0 (WCAG 2.0), the Marrakesh Treaty to Facilitate Access to Published Works for Persons Who Are Blind, Visually Impaired, or Otherwise Print Disabled (MVT), the Chafee Amendment to the US Copyright Act (17 USC § 121) or the so-called Chafee Amendment, and the Treaty Proposal on Limitations and Exceptions for Libraries and Archives of the International Federation of Library Associations and Institutions (IFLA) - referred to as IFLA's Treaty Proposal in this paper.

CRPD is an international framework enacted by the United Nations (UN) "...for the civil, cultural, economic, political and social rights of persons with disabilities on the basis of inclusion, equality and nondiscrimination..." (Office of the United Nations High Commissioner for Human Rights, 1996-2019). The Convention consists of 50 articles and those countries that choose to ratify the Convention are bound to incorporate the articles within their own national laws (Sieberns, 2014). The importance of the CRPD is that

Global J. Bus. Soc. Sci. Review 7 (2) 158 -165 (2019) 
it strengthens the link to the Sustainable Development Goals (SDGs) in the 2030 Agenda for Sustainable Development where disabled people are explicitly referred to in various goals, for instance, Goal 4 on quality education and the promotion of life-long learning opportunities for all, and Goal 10 on inequality reduction by empowering the inclusion of all in social, economic, and political aspects (CBM, 2016; United Nations, Department of Economic and Social Affairs, n.d.).

The World Wide Web Consortium (W3C) has recommended the use of the WCAG to make Web content more accessible for the benefit of general users and disabled people in particular. The WCAG has been developed from the WCAG 1.0 to WCAG 2.0, which is approved as an ISO standard: ISO/IEC 40500:2012 (Henry, 2018). The four principles promoted in the WCAG 2.0 are perceivability, operability, understandability, and robustness. To explain more clearly, the information and user interface are required to be presented in ways users could perceive it. The user interface and navigation also need to be operable. It is essential that the information and user interface are understandable. Finally, the content has to be compatible with various user agents, including assistive technologies (Caldwell, Cooper, Reid, \& Vanderheiden, 2010).

Exceptions to copyright (e.g. fair use or fair dealing) are useful tools to balance the interests of copyright holders and of the public. Many countries recognize the priority of disabled people and have enacted certain exceptions for them ("Digital Rights Management", 2005). Similarly, libraries, as information intermediaries, are granted exceptions to create accessible copies of data and make them available to disabled people (Diver \& Schafer, n.d.). However, the more digital technology has advanced, the greater concerns for copyright infringement have grown. The introduction of DRM and new copyright treaties by the World Intellectual Property Organization (WIPO), known as the Internet Treaties, have encouraged the protection of copyright in a new context, including anti-circumvention of DRM technologies (World Intellectual Property Organization, n.d.).

In line with the CRPD, the MVT has been adopted by WIPO. It is believed to act as a reconciliation between DRM technologies and web accessibility (Giannoumi et. al., 2017). This might be because it provides an international framework, seemingly similar to a permission to circumvent DRM technologies for the benefit of people with print disabilities. The MVT imposes an obligation on contracting parties to create a mandatory exception to copyright that permits people with print disabilities and authorized entities to "... undertake any changes needed to make a copy of a work in an accessible format..." for people with print disabilities, and, under certain conditions, allowing “...exchange across borders of those accessible copies produced..." (WIPO, 2016).

Likewise, the rule of anti-circumvention in the Digital Millennium Copyright Act (DMCA) makes bypassing DRM technologies illegal, even for legal purposes (Kasprowski, 2010). This creates imbalance among copyright holders and users. Nevertheless, in the case of disabled people, the Chafee Amendment, is often referred to as it grants permission to authorized entities to "...reproduce or to distribute in the United States copies or phonorecords of a previously published literary work or of a previously published musical work that has been fixed in the form of text or notation..." in accessible formats for use by blind people or those with visual impairments, perceptual or reading disabilities, and physical disabilities affecting their ability to hold/manipulate a book or move/focus their eyes for reading (Cornell Law School, Legal Information Institute, n.d.).

Following the MVT, the IFLA has also updated its Treaty Proposal. According to Article 10 of the Treaty, the right to use protected works and materials for the benefits of disabled people is highlighted. It provides libraries and archives the exceptions to the "...reproduction, transcription, translation, adaptation, distribution and communication to the public rights for the purposes of serving disabled people..." in "...both analogue and digital environment..." and "... allows the transfer or loan of an accessible copy made by one library or archive to another library or archive..." (International Federation of Library Associations and Institutions, 2013). 


\section{Research Methodology}

This study inspects the controversial interaction between accessibility to the Web and DRM among disabled people in accessing information on the Web using a document analysis method from a socio-legal perspective dealing with law and social phenomenon in the spirit of interdisciplinary and critical approaches. The study mainly uses the black-letter law of some widely known and internationally cited regulations for investigation and discussion. Those regulations include: The UN CRPD (United Nations, 2006); W3C's WCAG 2.0 (Caldwell et. al., 2010); WIPO's MVT (WIPO, 2016); the Chafee Amendment of the US (Cornell Law Scholl, Legal Information Institute, n.d.), and Section 10 of IFLA's Treaty (IFLA, 2013).

\section{Results}

After considering the related regulations relevant to disabled people's information access on the Web, with the implementation of DRM, it is found that a contradiction exists. In other words, the regulations in favour of access to the Web by disabled people appear to have been overruled and frustrated by the introduction of DRM. The challenges posed by DRM are briefly presented below.

\subsection{Negligence of Disabled People's Rights}

CRPD insists on the protection of disabled people's rights on the basis of inclusion, equality, and nondiscrimination (Office of the United Nations High Commissioner for Human Rights, 1996-2019). Contrary to this, DRM opposes some articles of the Convention, namely, Article 9 on Accessibility, Article 21 on Freedom of expression and opinion and access to information, and Article 30 on Participation in cultural life, recreation, leisure, and sport.

Article 9 includes proper measures to ensure disabled people's access to information and communications. This promotes appropriate forms of assistance and support to ensure disabled people have access to information. In addition, disabled people's access to new information and communications technologies and systems, including the Internet, is promoted. Moreover, it supports the design, development, production and distribution of accessible information and communication technologies and systems. However, when DRM is introduced, all of this appears inverse as DRM obstructs access to digital information.

It is indicated in Article 21 that disabled people should be ensured to the freedom to seek, receive and impart information and ideas through all forms of communications. To be specific, information and services, including the Internet, should be provided in accessible and usable formats appropriate to different types of disabilities. Since DRM controls access and use of digital information, the intention of this article could not be fulfilled in the Web environment.

Getting access to Web information is a means to participate in cultural life, recreation, leisure and sport. However, this could be impeded by DRM, particularly due to its underpinning purpose of anticircumvention, resulting in disagreement with Section 3 in Article 30 which provides that, "States Parties shall take all appropriate steps, in accordance with international law, to ensure that laws protecting intellectual property rights do not constitute an unreasonable or discriminatory barrier to access by persons with disabilities to cultural materials" (UN, 2006).

\subsection{Conflict of Accessibility}

Tim Berners-Lee, inventor of the Web and W3C Director, said that, "The power of the Web is in its universality. Access by everyone regardless of disability is an essential aspect" (World Wide Web Consortium, 2018). This is undoubtedly why W3C has created WCAG 2.0. However, while the standard reinforces the development of accessible Web content, DRM is in direct conflict with all four principles by 
creating inaccessible content and inoperable assistive technologies, due to its mechanism of prevention and restriction, fortified by legal prohibitions against its circumvention.

Illustratively, in respect of each principle, DRM acts in opposition to the following guidelines: Under perceivability, DRM may contravene the concepts of alternatives, adaptability, and distinguishability. Concerning operability, DRM may yield insufficient time to read and use content, cause difficulties for some hints of seizures, and encumber navigability. Respecting understandability, DRM may block some kinds of help, including assistive technologies, enabling disabled people, especially those with cognitive disabilities, to understand the content. Finally, DRM may interfere with robustness - the compatibility of content with assistive technologies, either hardware or software.

\subsection{Ignorance of Copyright-Related Exceptions}

Although the MVT, the Chafee Amendment, and Section 10 of IFLA's Treaty Proposal provide exceptions, which may be advantageous to disabled people's interests in accessing and using digital information in the Web environment, DRM supersedes the permissions provided by those exceptions. Notably, it could prevent the rights, pointed out in the exceptions, from being exercised in two major issues.

Firstly, the three exceptions to copyright allows either disabled people and authorized entities, in the case of the MVT, or just authorized entities alone, in the case of the Chafee Amendment and Section 10 of IFLA's Treaty Proposal, to adapt, reproduce, and distribute copyrighted works in accessible formats for disabled people. Additionally, the MVT and Section 10 of IFLA's Treaty Proposal supports the exchange of those copies. However, the adoption of DRM and its rule of anti-circumvention may inhibit these ideas and void the exceptions.

\section{Discussion}

The Preamble of CRPD emphatically requests the state parties to recognize "... the importance of accessibility to the physical, social, economic and cultural environment, to health and education and to information and communication, in enabling persons with disabilities to fully enjoy all human rights and fundamental freedoms..." (UN, 2006). DRM neglects disabled people's rights of accessibility as well as their freedom of expression and opinion, and access to information on the Web (W3C, 2018). This can be explained through the excessive prevention and restriction it exploits (e.g. encrypting copyrighted works (Harpur \& Suzor, 2013), disabling some features that assist in information access and use of disabled people (Puckett, 2010), or limiting their freedom of choice for DRM-compatible device (Writer, 2012)). As discussed above, together with the rule of anti-circumvention, disabled people's participation in cultural life, recreation, leisure, and sport is inevitably deprived in the Web environment.

Disabled people have different ways of surfing the Web, depending on their needs, preferences, and abilities - either for perceiving, interacting, making an input, or distinguishing and understanding (Zahra, 2017b). Web content should therefore be developed in conformity with accessibility standards, specifically the WCAG 2.0, to ensure that it is accessible by a variety of disabled people. Nevertheless, DRMencumbered content could, on the contrary, bring conflict to all principles advised by the guideline. This is because DRM puts some kinds of lock into effect for either hardware or software (Dingledy \& Matamoros, 2016). Consequently, Web content might not be perceivable, operable, understandable, and robust for the accessibility of disabled people. This is illustrated by the following examples: people with visual disabilities may not hear information via their screen-readers (Kramer, 2007); people with color-blindness may not be able to use their assistive tools to help distinguishing shades (Perry, 2017); and people with cognitive disabilities may not be able to change Web content to an "easy-to-read" version (Giannoumi et. al., 2017).

It is generally accepted that there is a diversity of disabilities, including visual, auditory, speech, physical, as well as cognitive, learning, and neurological disabilities (Zahra, 2017a). This could justify why they consume information differently in different forms, and often, adaptation to or modification of the 
information is imperative (Perry, 2017). The introduction and adoption of DRM on the Web not only hinders disabled people's use and access to information, but is greatly problematic due to its anti-circumvention rule. In other words, any effort to bypass DRM technologies, such as those for accessibility, are considered illegal (Giannoumi et. al., 2017). Even though there are some existing provisions regarding exceptions on copyright infringement in favour of disabled people's interests, namely, the MVT, the Chafee Amendment, and Section 10 of IFLA's Treaty Proposal, they are often disregarded. This may be due to ambiguities and controversies in practice, derived from legal documents, copyright holders' control, and technological limitations.

Firstly, some legal documents could cause hesitation and reluctance to the implementation of the exceptions. This could be clarified through the national laws of some countries where the anti-circumvention rule of DRM technologies is adopted (e.g. the DMCA of the US and the European Union's Copyright Directive (W3C, 2017)). In addition, the exceptions may be rendered meaningless for the sake of intellectual property or trade agreements ("Digital Rights Management", 2005; Giannoumi et. al., 2017; Nicholson, 2006; 29).

Further, copyright holder could purposefully control their copyrighted works, regardless of the exceptions, by placing restrictions on their digital media with DRM technologies (Diver \& Schafer, n.d.) or limiting devices that could be compatible to the technologies they use (Kasprowski, 2010). Further, the nullification of the exceptions could be in the form of licenses or contracts in which copyright holders establish conditions of access and use for their counterparts (Harpur \& Suzor, 2013; Helberger et. al., 2004; Neacsu, 2016).

Finally, owing to the limitation of DRM technologies to differentiate between legal and illegal actions to circumvent them (Doctorow, 2018), the exceptions could be overridden. Strictly speaking, some lawful DRM circumvention may include that for the purpose of accessibility, like captioning (Tran, 2016), generating subtitles and translations (Kastrenakes, 2017), as well as producing warnings for people with photosensitivity (Perry, 2017). However, as DRM technologies are measures on computers, they cannot make a judgment according to what is indicated in the exceptions, which could be varied across numerous legal regimes (Halpin, 2017). Therefore, the exceptions cannot be effective.

\section{Conclusion}

The right to access information is crucial for every society (Nicholson, 2006). Striking a balance between the interests of copyright holders and users of information is therefore important. This is exceptionally true in the case of disabled people, since information accessibility could increase their knowledge, productivity, and contribution, which can have a positive effect on everyone in society (Kramer, 2007). In light of the findings of this study, the following recommendations are made:

1) Copyright holders should realize the importance of disabled people's access to information on the Web and should make their work available in various accessible formats. Further, they should promote disabled people's accessibility by adopting less intrusive DRM measures, for example, DRM-free alternatives, particularly for disabled people and libraries, and Creative Commons (CC) licenses, which attempt to minimize the negative effects of DRM.

2) Effective implementation of copyright exceptions should be ensured and respected. In regard to disabled people's information access on the Web, both the exceptions to copyright for people with disabilities and libraries should not be undermined by DRM so that the rights to the benefits of their accessibility can be satisfactorily exercised.

3) Disabled people should be actively involved in the process of drafting any regulations related to their access to information on the Web. Libraries should also be involved. Including both parties in the process will ensure their concerns are respected and will result in practical regulations that are fair to them. 
It is suggested that further research be conducted for further insight into relevant topics. Since this study examines only the issue of DRM and its impact on disabled people's information access on the Web, some studies in the areas of DRM and learning sectors, such as formal education institutions and libraries, should be considered. Moreover, as DRM may have an impact worldwide, both in developed and developing countries, further comparative studies should be conducted.

\section{Acknowledgment}

The authors gratefully acknowledge the supporting funds for publishing this paper in the 9th Global Conference on Business and Social Science Series from the Graduate School of Law, National Institute of Development Administration; Research Section, Faculty of Arts, Chulalongkorn University; and the Suthilak Ambhanwong Memorial Fund.

\section{References}

Brewer, J. and Sajka, J. (2013). Accessibility Issues in Digital Publishing: Digital Rights Management, Accessibility Content, and User Interface Control. Retrieved from https:/www.w3.org/2012/08/electronic-books/submissions/ webooks2013_submission_41.html.

Caldwell, B., Cooper, M., Reid, L. G. and Vanderheiden, G. (Eds.). (2010). Web Content Accessibility Guidelines (WCAG 2.0). Retrieved from https://www.w3.org/WAI/GL/WCAG20/.

CBM. (2016). What Links Disability, Human Rights and the Sustainable Development Goals? Retrieved from https://www. cbm.org/fileadmin/user_upload/Publications/CRPD-A4LEAFLET-2-inhouseprint.pdf.

Cornell Law School, Legal Information Institute. (n.d.). 17 US code $§ 121$. Limitations on Exclusive Rights:

Reproduction for Blind or Other People with Disabilities. Retrieved from https://www.law.cornell.edu/uscode/text/17/121.

Daubs, M. S. (2017). HTML5, Digital Rights Management (DRM), and the Rhetoric of Openness. Journal of Media Critiques, 3(9), 77-94. Retrieved from https://www.researchgate.net/publication/313232499_HTML5_Digital_Rights_ Management_DRM_and_the_Rhetoric_of_Openness.

Digital Rights Management: A Failure in the Developed World: A Danger to the Developing World. (2005). Retrieved from https://www.eff.org/th/wp/digital-rights-management-failure-developed-world-danger-developing-world.

Dingledy, F. W. and Matamoros, A. B. (2016). What is Digital Rights Management? In C. A. Lemmer and C. P. Wale (Eds.), Digital Rights Management: The Librarian's Guide (pp. 1-25). Lanham, MD: Rowman and Littlefield.

Diver, L. and Schafer, B. (n.d.). Exceptions for Disability. Retrieved from https://www.copyrightuser.org/understand/ exceptions/disability/.

Doctorow, C. (2018, June 22). Disabilities vs DRM: The World Cup Edition [Blog?]. Retrieved from https://www.eff. org/deeplinks/2018/06/disabilities-vs-drm-world-cup-edition.

Ficsor, M. (2010). Protection of 'DRM' Under the WIPO 'Internet Treaties': Interpretation, Implementation and Application. in I. A. Stamatoudi (Ed.), Copyright Enforcement and the Internet (pp. 257-302). Alphen aan den Rijn, The Netherlands: Kluwer Law International.

Giannoumi, G. A., Land, M., Beyene, W. M. and Blanck, P. (2017). Web Accessibility and Technology Protection Measures: Harmonizing the Rights of Persons With Cognitive Disabilities and Copyright Protections on the Web. Cyberpsychology: Journal of Psychosocial Research on Cyberspace, 11(1), article 5. Retrieved from https:// doi.org/10.5817/CP2017-1-5.

Halpin, H. (2017). The Crisis of Standardizing DRM: The Case of W3C Encrypted Media Extensions. In S. Ali, J. L. Danger and T. Eisenbarth (Eds.), Security, Privacy, and Applied Cryptography Engineering: 7th International Conference, SPACE 2017, Goa, India, December 13-17, 2017, Proceedings (pp. 10-29). Cham, Switzerland: Springer. Retrieved from https://link.springer.com/chapter/10.1007\%2F978-3-319-71501-8_2.

Harpur, P. and Suzor, N. (2013). Copyright Protections and Disability Rights: Turning the Page to a New International Paradigm. UNSW Law Journal, 36(3), 745-778. Retrieved from https://ssrn.com/abstract=2390468.

Helberger, N., Kerényi, K., Krings, B., Lambers, R., Orwat, C., Riehm, U., Dufft, N. (2004). Digital Rights Management and Consumer Acceptability: A Multi-disciplinary Discussion of Consumer Concerns and Expectations. Retrieved from https://mpra.ub.uni-muenchen.de/id/eprint/6641. 
Henry, S. L. (Ed.). (2018). Web Content Accessibility Guidelines (WCAG) Overview. Retrieved from https://www. w3.org/WAI/standards-guidelines/wcag/.

International Federation of Library Associations and Institutions (IFLA). (2013). Treaty Proposal on Limitations and Exceptions for Libraries and Archives: Version 4.4. Retrieved from https://www.ifla.org/files/assets/hq/topics/ exceptions-limitations/tlib_v4_4.pdf.

Kasprowski, R. (2010). Perspectives on DRM: Between Digital Rights Management and Digital Restrictions Management. Bulletin of the American Society for Information Science and Technology, 36(3), 49-54. Retrieved from https://doi.org/10.1002/bult.2010.1720360313.

Kastrenakes, J. (2017, July 8). A DRM Standard Has Been Approved For The Web, and Security Researchers Are Worried. The Verge. Retrieved from https://www.theverge.com/2017/7/8/15942238/web-drm-standard-eme-approvedcontroversy.

Kramer, E. F. (2007). Digital Rights Management: Pitfalls and Possibilities for People with Disabilities. Journal of Electronic Publishing, 10(1). Retrieved from http://dx.doi.org/10.3998/3336451.0010.106.

Neacsu, D. (2016). DRM Redux. In C. A. Lemmer and C. P. Wale (Eds.), Digital Rights Management: The Librarian's Guide (pp. 173-194). Lanham, MD: Rowman and Littlefield.

Nicholson, D. R. (2006). Copyright - Are People With Sensory-disabilities Getting a Fair Deal? The Fourth PanCommonwealth Forum on Open Learning (PCF4). Retrieved from http://pcf4.dec.uwi.edu/viewpaper. php?id=379.

Office of the United Nations High Commissioner for Human Rights (OHCHR). (1996-2019). Human Rights of Persons with Disabilities. Retrieved from https://www.ohchr.org/en/issues/disability/pages/disabilityindex.aspx.

Perry, D. M. (2017, August 3). Are Internet Standards Standing in the Way of Digital Accessibility? Pacific Standard. Retrieved from https://psmag.com/social-justice/are-internet-standards-standing-in-the-way-of-accessibility.

Puckett, J. (2010). Digital Rights Management as Information Access Barrier. Progressive Librarian, 34/35, 11-24. Retrieved from https://scholarworks.gsu.edu/univ_lib_facpub/50/.

Sieberns, A. (2014). Access to Library Services is a Human Right. Retrieved from https://www.ifla.org/node/9192.

Tran, J. L. (2016). A Primer on Digital Rights Management Technologies. In C. A. Lemmer and C. P. Wale (Eds.), Digital Rights Management: The Librarian's Guide (pp. 27-48). Lanham, MD: Rowman and Littlefield.

United Nations (UN). (2006). Convention on the Rights of Persons with Disabilities. Retrieved from https://www.un. org/esa/socdev/enable/rights/convtexte.htm.

United Nations, Department of Economic and Social Affairs. (n.d.). Sustainable Development Goals (SDGs) and Disability. Retrieved from https://www.un.org/development/desa/disabilities/about-us/sustainable-development-goalssdgs-and-disability.html.

World Intellectual Property Organization (WIPO). (2016). Main Provisions and Benefits of the Marrakesh Treaty (2013). Retrieved from https://www.wipo.int/edocs/pubdocs/en/wipo_pub_marrakesh_flyer.pdf.

World Intellectual Property Organization (WIPO). (n.d.). WIPO Internet Treaties. Retrieved from https://www.wipo. int/copyright/en/activities/internet_treaties.html.

World Wide Web Consortium (W3C). (2017). Backgrounder on Encrypted Media Extensions (EME) at the World Wide Web Consortium (W3C). Retrieved from https://www.w3.org/2017/07/EME-backgrounder.html.

World Wide Web Consortium (W3C). (2018). Accessibility. Retrieved from https://www.w3.org/standards/ webdesign/accessibility.

Writer, S. (2012). Digital Rights Management (DRM) - A Digital Copyright Debate. Retrieved from http://www.business insurance.org/digital-rights-management-drm-a-digital-copyright-debate/.

Zahra, S. A. (Ed.). (2017a). Diverse Abilities and Barriers. Retrieved from https://www.w3.org/WAI/people-useweb/abilities-barriers/.

Zahra, S. A. (Ed.). (2017b). Tools and Techniques. Retrieved from https://www.w3.org/WAI/people-use-web/toolstechniques/. 